\title{
HISTÓRIA DA FORMAC̣ÃO DE PROFESSORES: DIÁLOGOS COM A DISCIPLINA ESCOLAR CIÊNCIAS NO ENSINO FUNDAMENTAL ${ }^{1}$
}

\begin{abstract}
RESUMO: O artigo apresenta um estudo histórico acerca dos cursos de Licenciatura na área de Ciências Naturais no Brasil e, em particular, das propostas de Licenciaturas Curtas implementadas nas décadas de 1960-70. Apoiado em referenciais do campo do currículo, problematizam-se relações e conflitos que se estabeleceram na proposição das licenciaturas curtas, relacionando-os com as demandas históricas por escolarização e com as especificidades da disciplina escolar Ciências. A análise dos argumentos produzidos no interior da comunidade acadêmica face a essas propostas e sustentados a partir de perspectivas epistemológicas e curriculares conflitantes é igualmente apresentada. Argumenta-se que o estudo da formação docente - suas concepções e modelos formativos - requer analisar tanto sua dimensão macrossocial quanto as relações mais específicas que configuram a disciplina escolar.
\end{abstract}

Palavras-chave: Educação em Ciências, História do Currículo, Formação de Professores de Ciências.

HISTORY OF THE INITIAL TEACHER TRAINING: DIALOGUES WITH THE SCHOOL SUBJECT SCIENCE IN ELEMENTARY SCHOOL

ABSTRACT: The article presents a historical study about the initial teaching training courses of science teachers in Brazil, especially some proposals implemented during the 1960-70, known as "Licenciaturas Curtas". The article discusses the conflicts that happened during the time of the proposals, relating them not only to historical schooling demands, but also to relationships between the courses and the school subject science. The discourses produced within the academic community showing conflicts among epistemological and curricular perspectives are also examined in the article. The historical analysis suggest that the study of the initial teacher training courses - their concepts and educational models - demands to take into consideration not only macro social perspectives but also specific relationships with the school subjects.

Keywords: Science education, Curriculum History, Initial training of Science teachers. 


\section{INTRODUĈ̣̃O}

A problemática que envolve a qualidade da educação básica no país, amplamente conhecida, vem desafiando as políticas públicas no sentido de buscar caminhos que coloquem o Brasil em melhores condições de competitividade em um contexto de economia globalizada. Ao pensar nos diferentes aspectos da questão educacional - avaliação, financiamento, currículo, livros didáticos, acesso e permanência etc. -, os professores não poderiam ficar de fora. Algumas vezes considerados heróis, e em outras, vilões, esses atores estão no centro das políticas educacionais, seja no que tange à formação continuada, seja à formação inicial. Assim sendo, desde o final dos anos de 1990, vêm-se implantando profundas reformas no modelo de formação de professores no Brasil.

Refletir sobre os desafios colocados ao modelo de formação docente em nível superior no Brasil, a nosso ver, implica situarmos o contexto político-econômico das reformas, bem como a demanda por escolarização da população ao longo de sua história. Pensar sobre a formação de professores, especialmente de Ciências e Biologia, implica também acrescentar a esses dois elementos um outro, inerente à especificidade dessas disciplinas escolares. Em que condições sócio-históricas a formação dos professores dessas disciplinas se forjou frente à instituição da universidade no Brasil? Quais relações vêm se estabelecendo entre as políticas curriculares para a formação de professores de Ciências e Biologia e a escola (ou as disciplinas escolares)?

A complexidade dessas questões e as discussões que suscitaram sobre a formação de professores para as disciplinas do ensino secundário ${ }^{2}$ caminharam $^{-}$ juntamente com o debate acerca da universitarização do ensino superior brasileiro. Como discutiremos ao longo do texto, desde o final dos anos 1920 e o início da década de 1930, a formação docente vem sendo colocada no centro desse debate. Expressam-se não somente concepções diferenciadas acerca dos sentidos do formar e desenhos curriculares que materializam essas concepções, como também relações com as especificidades da escola.

Neste texto, situaremos historicamente os cursos de Licenciatura no Brasil, procurando compreendê-los frente às demandas sociais em diferentes momentos, dando destaque aos cursos de Licenciatura na área de Ciências Naturais. Articulamos, assim, o panorama histórico, o contexto político-econômico, a partir dos anos 1930, a demanda por escolarização e as especificidades da disciplina escolar Ciências, que surge nesse período. Por meio dessa problematização, desejamos assinalar que o estudo da formação docente - suas concepções e modelos formativos - demanda analisar tanto sua dimensão macrossocial quanto as relações mais específicas que configuram a disciplina escolar mencionada.

\section{PROCESSOS DE INSTITUCIONALIZAC̣ÃO DA FORMAC̣̃̃O DOCENTE}

A formação de professores do nível secundário é marcada por uma trajetória que evidencia descompasso entre os tempos nos quais o sistema escolar e 
as universidades brasileiras se institucionalizam. Enquanto o ensino secundário organizou-se de forma centralizada a partir da fundação do Colégio Pedro II, em 1837, a formação dos professores desse nível escolar não teve início antes da década de 1930. Até então, os professores eram recrutados entre aqueles formados nos cursos superiores existentes. Foi na esteira da efervescência cultural dos anos 1920, na qual se destacam a poesia, as artes plásticas, o cinema, a arquitetura, a ciência e a educação, que ganha força a ideia da necessidade de uma formação voltada para a atuação no magistério do ensino secundário ${ }^{3}$. Assim, a Reforma do Ensino Secundário é precedida do estabelecimento, poucos dias antes, do primeiro Estatuto das Universidades Brasileiras. Esse movimento de reformas no campo educacional é fruto de um amplo movimento gestado pelas elites intelectuais que sonhavam com um Brasil urbano e moderno (LIMONGI, 2001; DÁVILA, 2006).

Naquele momento, diferentes projetos políticos e diferentes concepções de educação e de universidade disputavam hegemonia, principalmente no Rio de Janeiro e em São Paulo. O Estatuto das Universidades Brasileiras, elaborado por Francisco Campos, trazia uma dessas concepções. Para ele, o caráter verdadeiramente universitário seria dado pela criação, no interior da universidade, da Faculdade de Educação, Ciências e Letras, local onde se realizariam os estudos desinteressados, voltados para os altos e autênticos valores da cultura ${ }^{4}$. Apesar da enfática defesa dessa Faculdade, ela não chegou a sair do papel.

Três outros projetos chegaram a ser concretizados. O primeiro, liderado por Fernando de Azevedo, deu origem à Universidade de São Paulo, em 1934. Nesta universidade, a Faculdade de Filosofia, Ciências e Letras era responsável pela base científico-acadêmico-cultural dos estudantes, desvinculada de uma preocupação com a formação profissional. A formação profissional para o magistério se dava no Instituto de Educação, que compunha a Universidade ${ }^{5}$.

O segundo projeto, liderado por Anísio Teixeira, foi implantado no Rio de Janeiro, na época Distrito Federal, em 1935: a Universidade do Distrito Federal (UDF). Na concepção de Teixeira, a Escola de Educação ${ }^{6}$ tinha papel central na Universidade e a formação dos professores se daria em articulação entre esta e as demais Escolas responsáveis pela formação do conhecimento específico. Apesar da separação desses espaços, o modelo anisiano buscava uma ampla articulação, não apenas entre os campos do conhecimento envolvidos na formação do professor, como também entre os diferentes níveis de ensino. A experiência da UDF durou o tempo suficiente para formar a primeira turma de professores (VICENZI, 1986) ${ }^{7}$.Em 1939 foi extinta, passando seus estudantes e alguns de seus professores para a recém-criada Faculdade Nacional de Filosofia (FNFi) da Universidade do Brasil ${ }^{8}$.

Foi nessa Universidade, então, que o terceiro projeto de formação de professores foi implantado e se tornou hegemônico, servindo como modelo para as demais universidades do país. Na FNFi conviviam as Seções ${ }^{9}$ responsáveis pelos conhecimentos específicos voltados para a formação de bacharéis nas diferentes áreas e a Seção Especial de Didática, responsável pela formação pedagógica e pro- 
fissional para o magistério. A FNFi, no entanto, repetia e acabou por consolidar o chamado "modelo $3+1$ " para a formação de professores, criado pela USP, no qual, após três anos do curso em uma área específica, obtinha-se o diploma de bacharel. Com mais um ano de formação pedagógica, obtinha-se o diploma de licenciado ${ }^{10}$. Esse modelo deveria, por força de lei, ser seguido em todo o país.

Nesse modelo, então, foram formados, conjuntamente, as gerações de professores e de cientistas brasileiros dentro de um padrão direcionado para áreas específicas. Isso explica, em parte, a tensão permanente existente entre o bacharelado e a licenciatura nas universidades brasileiras ${ }^{11}$. É esse modelo de separação entre os dois campos de conhecimento necessários à formação docente - o específico, voltado para o mundo científico-cultural, e o pedagógico, voltado para a formação didático-profissional - que marca a formação dos professores até os dias de hoje ${ }^{12}$.

É preciso destacar que à medida que se configuravam as primeiras experiências de formação docente nas universidades, a comunidade científica ia se expandindo e se institucionalizando para além dos quadros constituídos, por exemplo, no Instituto Oswaldo Cruz, em Faculdades de Medicina e de Engenharia, e nos museus, como o Museu Nacional ${ }^{13}$. Nesse contexto, hegemoniza-se a comunidade científica sobre a docente, ameaçando a identidade e o lugar da formação de professores no seu nascedouro, deixando marcas que acompanham sua trajetória desde então. Estas marcas expressam-se não somente no modelo de preparação dos professores, mas igualmente nas disputas sobre as decisões curriculares para o ensino de ciências, como veremos adiante.

Considerando aqui o modelo instituído na FNFi, a formação de professores para o ensino secundário se dava, no caso da área de ciências naturais, através do Setor de Ciências, responsável pelos conhecimentos específicos, e era complementada pela Seção Especial de Didática, que oferecia o chamado "Curso de Didática”, o qual se agregavam aos conhecimentos específicos já adquiridos os conhecimentos pedagógicos sobre o como ensinar, tendo como ênfase a Psicologia, a Didática propriamente dita e a legislação educacional. A concepção de professor vigente era essencialmente daquele que dominava os conhecimentos da disciplina que iria ensinar e as técnicas necessárias para garantir a aprendizagem.

É necessário considerar que o ensino secundário constituía-se em um nível de ensino ainda muito restrito, passando por um lento processo de expansão. Mesmo assim, o número de egressos que se dedicaria ao magistério não correspondia à demanda, sendo insuficiente para suprir as necessidades de expansão da escola (NUNES, 2000). Boa parte dos professores formados naquele período pela FNFi tornou-se professor da própria instituição ou ocupou cargos na burocracia do Estado. Alguns dos professores que lecionavam no ensino secundário o faziam no Colégio Pedro II, instituição de referência para a educação nacional, e acumulavam esse cargo com o de professor da FNFi. Ou seja, o ensino secundário existente se misturava ao incipiente ensino superior universitário. Mesmo com o Decreto-Lei 1.190/39, que estabeleceu o prazo de $1^{\circ}$ de janeiro de 1943 para que o preenchimento de qualquer cargo ou função no magistério secundário 
ou normal fosse feito apenas com portadores de diploma de licenciado do curso correspondente à disciplina que fosse lecionar, tal exigência deve ser vista com prudência, uma vez que muitos professores continuavam sendo aprovados com base em clientelismo e a diplomação não era o critério padrão (DÁVILA, 2006). Até a década de 1960 a formação de professores sofreu poucas transformações em relação à sua concepção. As discussões que se travavam na FNFi diziam respeito ao aumento da duração do bacharelado de três para quatro anos. Esse aumento, no entanto, justificava-se pela necessidade de melhorar a qualidade da formação de professores (BONARDI, 1990).

A concepção dos cursos de licenciatura como um apêndice dos cursos de bacharelado prevaleceu sem grandes questionamentos até as décadas seguintes. A Reforma Universitária de 1968 agravou mais o quadro de fragmentação, ao separar os dois loci da formação ${ }^{14}$ : institutos específicos e Faculdades de Educação. Esse formato de licenciatura voltava-se para a formação de uma elite social reduzida. Os professores que efetivamente atendiam à expansão da escola, intensificada na década de 1960, não provinham desses cursos - nem das universidades públicas e nem das faculdades isoladas - principalmente nas áreas científicas, mantendo-se, ainda nesse período, o criticado improviso na formação de professores $^{15}$. A ampliação cada vez mais intensa do acesso à escola vai agravando o quadro de reprovação e evasão, aumentando o desafio que a sociedade impunha à escola. Foi preciso pensar em outro modelo de formação, principalmente para atender a especificidade do primeiro ciclo do ensino secundário. Esse novo modelo foi chamado de licenciatura de primeiro ciclo, e sua implantação esteve intimamente relacionada ao movimento de renovação do ensino de Ciências.

\section{FORMAC̣ÃO DE PROFESSORES E ENSINO DE CIÊNCIAS}

A trajetória da formação docente voltada ao ensino de Ciências no nível fundamental configura-se como um caso peculiar que precisa ser compreendida na sua articulação com transformações importantes tanto nas ciências e na sociedade quanto nas propostas curriculares que têm lugar no Brasil a partir dos anos 1930. Nesse período, concomitante ao surgimento dos cursos de licenciatura nas recém-criadas universidades brasileiras, destaca-se a emergência da disciplina escolar Ciências, que surge oficialmente no currículo do ensino secundário com a Reforma Francisco Campos. Essa reforma também reorganiza a escolaridade, dividindo o nível secundário em dois ciclos, em um total de sete anos. No primeiro ciclo, chamado de "fundamental" e com cinco anos de duração, essa disciplina recebe a denominação de Ciências Físicas e Naturais ${ }^{16}$, passando a ser oferecida nas duas séries iniciais. Nas séries seguintes, ocorre a especialização, passando a ser oferecidas as disciplinas Física, Química e História Natural isoladamente em cada uma das séries ${ }^{17}$. No ciclo complementar é mantida a especialização, variando a combinação das disciplinas de acordo com o curso superior 
que o estudante pretendesse cursar (Direito; Medicina, Odontologia e Farmácia ou Engenharia e Arquitetura $)^{18}$. Como veremos ao longo desta seção, as particularidades da disciplina Ciências desafiarão as possibilidades de formação dos professores para lecioná-la nas décadas que sucederam à sua criação.

Segundo Ferreira (2005), desde sua criação, a disciplina escolar Ciências Físicas e Naturais foi portadora de uma ideia que a acompanhará até os dias atuais: seria pedagogicamente interessante iniciar os estudantes no estudo das ciências por meio de um ensino integrado. Fundamentava essa ideia a visão positivista de que as diversas ciências possuíam um método único, o que justificaria essa reunião para fins de ensino. Os estudos de Macedo e Lopes (2002) sobre os rumos sócio-históricos da disciplina escolar Ciências no Brasil argumentam que essa disciplina assumiu um papel de introdução geral ao estudo das ciências, a exemplo do surgimento da General Science nos currículos escolares norte-americanos, priorizando interesses mais próximos dos alunos. A despeito do seu caráter introdutório, da ênfase integradora e de estar voltada para os interesses dos estudantes, o predomínio de metodologias passivas e conteudistas que marcavam não somente essa, mas igualmente o ensino das ciências, foram consideradas inadequadas e desatualizadas. Como veremos mais adiante, foi no âmbito dessas críticas que ganharam centralidade, em nosso país, os debates que defendiam metodologias experimentais para o ensino das disciplinas científicas, e que colocavam em xeque a formação de professores.

O descontentamento com os métodos e conteúdos dessas disciplinas escolares encontrou ressonância em um movimento de caráter internacional, liderado pelos Estados Unidos e Inglaterra, conhecido como "movimento de renovação do ensino de ciências” (BARRA e LORENZ, 1983; KRASILCHIK, 1987; FERREIRA, 2005; SELLES, 2008). Resumidamente, ressaltamos que esse movimento, que teve início no final da década de 1950, foi marcado por grandes investimentos para o desenvolvimento de novos programas curriculares, conhecidos por suas iniciais ${ }^{19}$. No clima de guerra fria, no qual a aliança Estados Unidos-Inglaterra disputava a hegemonia sobre os demais países com a União Soviética, o lançamento do satélite artificial soviético Sputnik 1, em 1957, provocou a ampliação de reformas educacionais norte-americanas com amplo financiamento federal. Esse movimento visava ao aumento da produção científico-tecnológica, relacionando-o à melhoria do ensino científico nas escolas. Dessa forma, decisões curriculares foram implementadas, buscando imprimir novas direções para o ensino das ciências e da Matemática naqueles países e em outros sob suas influências, com grande aposta na produção de materiais didáticos.

Autores como Krasilchik (1987), Selles (2008) e Selles e Ferreira (2008) destacam que no Brasil esse movimento de renovação inicia-se pela ação de um grupo de cientistas, especialmente quando é criada a seção científica do IBECC nos anos $1950^{20}$. Esse grupo conta com o apoio da UNESCO e com recursos financeiros provenientes das fundações Rockefeller, Ford, Agência Panamericana e Agência Norte-Americana para o Desenvolvimento Internacional (USAID), 
em um esforço de renovar métodos e conteúdos de ensino. A perspectiva inicial do movimento brasileiro, de atualizar os conhecimentos ensinados na escola secundária, considerados muito defasados, passou, nas décadas seguintes, a incorporar plenamente os objetivos do movimento internacional, ou seja, levar os alunos a vivenciarem o processo de investigação científica, por meio da "prática" do método científico. A produção de materiais didáticos com essa ênfase era considerada a maneira mais eficiente de alterar o comportamento dos professores, fazendo com que as atividades experimentais, e, principalmente, o "método da redescoberta" ${ }^{21}$, entre outras atividades, se tornassem uma realidade nas escolas (SELLES e FERREIRA, 2008).

É preciso destacar que, no quadro nacional, todo esse movimento específico na área de Ciências caminhou na direção de tentar melhorar a qualidade da educação. O aumento da demanda, fruto do processo de modernização e urbanização em curso no país, vinha pressionando a estreita oferta quantitativa e qualitativa de ensino, exigindo uma política reformista que enfrentasse os problemas de evasão e repetência que já se tornavam evidentes na década de 1960 (ROMANELLI, 1984). Dentre as iniciativas governamentais, destacam-se o "Programa Jovem Talento ou Jovens Talentos?”, a implementação das Feiras de Ciências e a criação dos Centros de Ciências para produção de materiais didáticos e formação continuada de professores. Na década de 1970 uma importante ação de formação de professores em serviço é também desenvolvida pelo Estado. Trata-se do Projeto Nacional para a Melhoria do Ensino de Ciências (PREMEN), que visava ao aperfeiçoamento dos professores de ciências e Matemática, mantendo a ênfase no ensino experimental, na produção de materiais didáticos e de kits de cunho experimental para as escolas. Juntou-se ao PREMEM o trabalho desenvolvido nos diversos Centros de Ciências criados em vários estados brasileiros em articulação com o IBECC.

Tanto as ações do IBECC quanto as iniciativas do PREMEN estavam voltadas, prioritariamente, para os professores em exercício, pois poucos possuíam formação adequada para atuar no ensino das matérias científicas, dada a carência generalizada de professores. Situação mais crítica encontrava-se na disciplina escolar Ciências, ministrada no primeiro ciclo do ensino secundário, chamado de ginásio a partir da Lei 4.024/61, para a qual não havia formação apropriada. Isto porque a licenciatura em História Natural ${ }^{22}$ não oferecia disciplinas que preparassem os futuros professores a atuarem no primeiro ciclo. Mesmo as mudanças que originaram a licenciatura em Ciências Biológicas, em 1963, não davam conta plenamente da especificidade do ensino de Ciências nesse ciclo. A licenciatura em Ciências Biológicas, portanto, estabelecia vínculos mais evidentes com as características propedêuticas do ensino científico no segundo ciclo do secundário em detrimento do primeiro, que se ocupava de uma introdução geral e integrada para o estudo das ciências. Assim, se de um modo geral era preciso enfrentar o problema da formação inicial de professores, de modo específico o primeiro nível de ensino apresentava carências muito prementes. 


\section{FORMAC̣̃̃O DOCENTE E DISCIPLINA ESCOLAR CIÊNCIAS NO ENSINO FUNDAMENTAL: TENTATIVAS DE APROXIMAÇÃO}

Cabe destacar ainda que, na década de 1960 - o que parece ser uma constante na história da educação brasileira -, além da falta de inscritos nos cursos de licenciatura, muitos professores formados migravam para outras atividades devido à baixa remuneração na carreira do magistério (PEPE, 1976). Tal quadro aprofundava a carência de professores e pressupunha a busca urgente de soluções. Uma das tentativas é a criação, em 1965, do curso de Licenciatura de $1^{\circ}$ ciclo, ou Licenciatura Curta em Ciências, com carga horária menor do que a oferecida no curso de História Natural e, posteriormente, de Ciências Biológicas ${ }^{23}$. Entretanto, o projeto inicial das licenciaturas curtas em Ciências de 1965 é abandonado em meio à instauração da ditadura militar, emergindo em seu lugar uma segunda edição, no bojo das reformas instituídas pela Lei 5692/71. Apesar de guardarem semelhanças, cada um dos projetos responde de modo diferenciado às carências de professores e às características próprias da disciplina escolar.

A Licenciatura Curta em Ciências tinha como objetivo formar professores para lecionar tanto Ciências quanto Matemática no curso ginasial, constituindo-se em uma proposta de formar um professor "polivalente", isto é, habilitado nas duas disciplinas mencionadas. Segundo o Parecer N. ${ }^{\circ}$ 81/65, esse curso visava reduzir, assim, a carência de professores, que era suprida, até então, por meio dos exames de suficiência, os quais habilitavam os professores não licenciados, mas em exercício na função. Cabe destacar que a Licenciatura Curta em Ciências dos anos 1960 mantém forte vínculo com o bacharelado e as demais licenciaturas da área, o que fazia com que seu prestígio diante dos outros cursos fosse relativamente preservado, pois o curso encontrava-se ligado a uma matriz única dos currículos de licenciatura e bacharelado. Segundo Ayres et al (2008, p. 10) tal articulação curricular

implicava formar professores para atuar no ginásio sem retirar-lhes totalmente o status acadêmico. Assim, tais cursos apresentavam-se como uma possibilidade alternativa aos cursos de Licenciatura em História Natural e em Ciências Biológicas, fato que talvez tenha sido importante para que, na sua primeira edição, não houvesse resistência à sua implantação.

Além disso, é preciso destacar que o projeto inicial da Licenciatura Curta em Ciências naquele período ainda estava marcado pelo processo de democratização do país, o que originou a Lei de Diretrizes e Bases da Educação de 1961. Constituía-se como projeto emergencial, visando suprir a carência de professores, porém, sem diferenciá-los profundamente daqueles formados pela licenciatura plena. Esse panorama, no entanto, irá se modificar na década de 1970.

A Licenciatura Curta em Ciências, proposta na década seguinte, mantém a ideia de polivalência e o tempo reduzido para a conclusão do curso, entretanto, radicaliza sua forma de implantação. Distinta da proposta dos anos 1960, a Resolução 30/74 rompe a vinculação com a licenciatura plena e com o bacharelado, assumindo-se como uma trajetória obrigatória e curricularmente independente. Se 
a Licenciatura Curta proposta anteriormente era uma possibilidade alternativa aos cursos plenos, o caráter obrigatório da nova edição, a ser efetivado até 1978, provocou fortes reações na comunidade científica e educacional. Entre posições favoráveis e contrárias à proposta, o caráter obrigatório colocava em xeque as questões mais amplamente relacionadas à política de governo para a formação docente. Além disso, oposições e adesões voltavam-se igualmente para a natureza epistemológica do curso. Não apenas se rejeitava a formação aligeirada e descomprometida com a qualidade do ensino, como também o valor pedagógico de uma formação sustentada pela ideia de integração das ciências - também chamada de "ciência integrada" - uma expressão do Positivismo Lógico ${ }^{24}$. Dessa forma, focalizavam-se princípios epistemológicos, ignorando, em certa medida, como o caráter integrador da disciplina escolar Ciências encontrava-se enraizado à história dessa disciplina.

\section{CONSIDERACְ̃̃ES FINAIS}

Se for cabível sugerir que segmentos hegemônicos da comunidade científica opuseram-se à natureza macrossocial da proposta da Licenciatura Curta de Ciências nos anos 1970, reagindo ao tratamento descomprometido com a formação docente, o mesmo não pode ser dito em relação às críticas de ordem epistêmico-pedagógica. Isto porque, se havia mais concordâncias de que o tempo de duração de dois anos proposto ao curso era insuficiente para uma formação conceitual sólida, tanto as oposições quanto as adesões ao ensino integrado evidenciavam compreensões particulares sobre as relações entre a formação acadêmica e a disciplina escolar. Os argumentos contrários ao ensino integrado - em muitos casos elaborados de forma consistente como, por exemplo, os de Cunha (1977) e Hamburger (1983) - parecem ter tratado, de forma indistinta, razões de ordem epistemológica e pedagógica, deixando de examinar características históricas da disciplina escolar Ciências, tais como seu caráter introdutório aos conhecimentos científicos e sua organização não especializada dos conteúdos (FERREIRA, 2005; LOPES E MACEDO, 2002). Assim, como argumentamos anteriormente (AYRES et al, 2008), a despeito das restrições ideológicas e da proposta curricular acanhada, as licenciaturas curtas representaram uma primeira tentativa de formação voltada especificamente para a disciplina escolar Ciências.

O autoritarismo vigente, as intrincadas relações das licenciaturas curtas com interesses privados e as ameaças ao tratamento irresponsável das políticas de formação docente que traziam formaram uma agenda da comunidade científica contra o regime ditatorial. A união em torno desse ideário teve nas associações científicas $^{25}$ seu espaço de enfrentamento e conseguiu enfraquecer os cursos curtos, barrando-os em muitas universidades federais para, posteriormente, derrotá-los. Se a participação dos cientistas foi fundamental para o confronto com o projeto ideológico que sustentava essas propostas, por sua vez, centralizou o debate em uma leitura particular das relações entre formação docente, ciência e 
escola. A defesa de maior aproximação das ciências de referência na formação de professores mantinha aceso o ideário do movimento de renovação do ensino de Ciências, reiterando os argumentos a favor do ensino experimental e de metodologias inspiradas nas práticas científicas.

Dessa forma, estudos recentes sugerem que as licenciaturas curtas de Ciências, a despeito de serem compreendidas como políticas de atendimento emergencial à carência de professores, dentro de um quadro macrossocial e econômico que aligeirava a formação docente, precisam também ser estudadas nas relações com a disciplina escolar (LIMA-TAVARES, 2006; LIMA-TAVARES e SELLES, 2007; AYRES et al, 2008). Naquele momento histórico, a rejeição à Licenciatura Curta postergava um debate sobre a especificidade de uma formação docente voltada à disciplina Ciências. As experiências recentes de implantação de cursos de licenciatura em Ciências não podem se furtar a retomar esse debate.

\section{NOTAS}

${ }^{1}$ Este trabalho é resultado da articulação de dois projetos de pesquisa. O primeiro deles, "A Faculdade de Formação de Professores em São Gonçalo: movimentos de uma história em construção (1971-1987)", é financiado pela FAPERJ, e o segundo, "Experimentação no ensino de Biologia: matrizes históricas e curriculares na formação de professores", financiado pela FAPERJ e pelo CNPq, respectivamente, sob coordenação da primeira e da segunda autora. Ambos são realizados no âmbito do grupo de pesquisa "Currículo, Docência e Cultura", na Universidade Federal Fluminense.

${ }^{2} \mathrm{O}$ ensino secundário, desde o final do século XIX até meados do século XX, correspondia aos níveis escolares que sucediam o ensino primário (ROMANELLI, 1984).

${ }^{3}$ Até a criação dos primeiros cursos de licenciatura - e mesmo depois - o ingresso no magistério secundário se dava através de exame realizado pelo Estado. Não havia, até então, cursos superiores voltados para o preparo profissional dos professores (ANDRADE; AYRES; SELLES, 2004; AYRES, 2006).

4 “Exposição de Motivos do Ministro Francisco Campos sobre a Reforma do Ensino Superior”. In: FÁVERO, 2000.

${ }^{5}$ Essa separação dos espaços destinados à formação específica e pedagógico-profissional terminou quando a USP teve que se adequar ao Estatuto das Universidades Brasileiras estabelecido por Francisco Capanema no período da ditadura varguista, conforme explicitaremos mais adiante.

${ }^{6}$ Originada a partir do Instituto de Educação do Rio de Janeiro que foi incorporado à UDF.

${ }^{7}$ Neste texto não nos ocupamos de uma discussão sobre o processo de fechamento da UDF e da criação da FNFi, que teve lugar no governo Vargas. A esse respeito, consultar Vincenzi (2010).

${ }^{8}$ Atualmente Universidade Federal do Rio de Janeiro.

${ }^{9}$ A estrutura da FNFi foi montada a partir de quatro Seções e 11 cursos: Seção de Filosofia (curso de Filosofia); Seção de Letras (cursos de Letras Clássicas, Letras Neolatinas e Letras Anglo-Germânicas); Seção de Ciências (cursos de Matemática, Química, Física, História Natural, História 
e Geografia e Ciências Sociais); Seção de Pedagogia (curso de Pedagogia) e, por último, a Seção Especial de Didática (curso de Didática).

${ }^{10}$ É importante ressaltar que, apesar de o modelo preconizar a formação do licenciado subsequente à formação do bacharel, até 1941, era permitido cursar disciplinas dos dois campos simultaneamente, o que foi proibido com o Decreto-Lei 3.454/41.

${ }^{11}$ As atas de reuniões de colegiados e congregações da FNFi dessa época demonstram as disputas entre esses dois campos em discussões curriculares (AYRES, 2006).

${ }^{12} \mathrm{O}$ desmembramento das seções da FNFi e a criação de institutos específicos só vai ocorrer com a Reforma Universitária de 1968. Assim, aumenta a fragmentação na formação de professores.

${ }^{13}$ Cabe refletir, como defende Dominichi Miranda de Sá, que o "paradigma universitário", ao sustentar a fundação da ciência brasileira nos anos 1930, silencia uma produção científica anterior a esse período, secundarizando essa produção e as disputas entre diferentes tradições intelectuais. Segundo a autora, enquanto novos discursos e novos parâmetros para a carreira científica "buscavam se firmar" os herdeiros da tradição anterior "insistiam em resistir" (SÁ, 2006, p. 31).

${ }^{14}$ Podemos inserir um terceiro locus: o Colégio de Aplicação, onde ocorre o estágio dos licenciandos. As Faculdades de Filosofia foram obrigadas a manter uma escola especificamente voltada para a prática docente dos licenciandos, chamada de Ginásio de aplicação. Essa obrigatoriedade foi instituída em 1946 pelo Decreto-Lei no 9.053 (BONARDI, 1990).

${ }^{15}$ Isso se confirma pela necessidade de capacitação em serviço realizada por órgãos federais, como a CADES, que visavam dar alguma formação aos professores. (NUNES, 2000).

${ }^{16}$ Decreto no 20.158 - 18 de abril de 1931.

${ }^{17}$ Ao longo do artigo, veremos que da década de 1930 à década de 1960 o ensino secundário sofreu poucas alterações. Em 1942, o primeiro ciclo é reduzido para quatro anos, sendo a disciplina Ciências Naturais oferecida apenas nas duas séries finais. O segundo ciclo, dividido em Clássico e Científico, e com três anos de duração, oferecia, no Clássico, Física e Química, nas duas séries finais, e Biologia, apenas na última série e, no Científico, Física e Química, nas três séries, e Biologia, nas duas últimas. Em 1946, a disciplina Biologia é substituída por História Natural nos dois cursos. A Lei 4.024/61, apesar de permitir maior flexibilidade curricular, mantém a estrutura já existente e passa a adotar a designação "Ensino Médio" para o ensino secundário.

${ }^{18}$ Nesse segundo ciclo há uma variação de denominação da disciplina escolar atualmente considerada como Biologia, para História Natural, Biologia Geral e Higiene. Assim, essas compõem o currículo do ciclo secundário, além das disciplinas Física e Química. Essas denominações refletem concepções diferentes tanto do currículo quanto das Ciências Biológicas como campo do conhecimento, cuja discussão foge ao objetivo deste trabalho. Estudos sobre a história das disciplinas escolares História Natural e Biologia podem ser conferidos em Cassab (2011) e Cassab e Selles (2008).

${ }^{19}$ Dentre os mais conhecidos, destacam-se: BSCS, Biological Sciences Curriculum Study; Physical Science Study Committee, conhecido como PSSC Physics; o Chemical Education Materials Study, conhecido como Chem Study; o Earth Sciences Curriculum Project, conhecido como ESCP (ver KRASILCHICK, 1987; SELLES, 2008).

${ }^{20}$ O Instituto Brasileiro de Educação, Ciência e Cultura, IBECC, foi criado em 1946. A comissão paulista foi inaugurada em 1950 e, posteriormente, Isaías Raw assumiu a presidência da seção cientí- 
fica. Posteriormente, em 1967, é fundada a Fundação Brasileira para o Desenvolvimento do Ensino de Ciências, FUNBECC, ligado ao IBECC e destinado à comercialização do material didático produzido pelo Instituto (SELLES, 2008).

${ }^{21} \mathrm{O}$ método da redescoberta configurava-se como uma proposta pedagógica que defendia que a reprodução dos procedimentos científicos - o domínio de métodos e conteúdos atualizados, oriundos da comunidade científica - na escola, melhoraria o aprendizado. Assim, propunha ensinar aos estudantes como formular questões, buscar evidências e avaliar os resultados de suas próprias investigações. O conjunto de propostas pedagógicas espelhadas na atividade científica, tais como discussões, trabalhos em grupo, leituras e análises de artigos científicos e, principalmente, atividades laboratoriais, permitiria aos alunos "descobrirem” os conceitos teóricos básicos da Ciência (DEBOER, 1991).

${ }^{22}$ Esse curso, além dos conteúdos das Ciências Biológicas, apresentava uma forte ênfase nas Geociências.

${ }^{23}$ Foram aprovados pelo Parecer no 81/65 do Conselho Federal de Educação três cursos de licenciatura curta para professores do então ciclo ginasial: (i) Línguas; (ii) História, Geografia e Organização Política e Social; e (iii) Ciências Fisicobiológicas e Matemática (Documenta, n. ${ }^{\circ} 38$, junho de 1965). Este último ficou conhecido como Licenciatura Curta em Ciências.

${ }^{24}$ Corrente de pensamento filosófico difundida nas primeiras décadas do século XX, defendia que o conhecimento válido era o que se apoiava basicamente na realidade empírica, em princípios de neutralidade e desprovido de subjetividade. Tinha como perspectiva a possibilidade de unificar todas as ciências em torno de um método comum.

${ }^{25}$ Referimo-nos à Sociedade Brasileira para o Progresso da Ciência (SBPC), à Sociedade Brasileira de Física (SBF) e à Associação Nacional de Pesquisa e Pós-Graduação em Educação (ANPEd).

\section{REFERÊNCIAS BIBLIOGRÁFICAS}

ANDRADE, Everardo Paiva de; AYRES, Ana Cléa Moreira; SELLES, Sandra. E. Não só do seu préstimo, mas dos seus costumes: provisão e formação de professores no Brasil. ENCONTRO DE PESQUISA EM EDUCAÇÃO DA REGIÃO SUDESTE - POLÍTICA, CONHECIMENTO E CIDADANIA, 6., 2004, Rio de Janeiro. Anais... Rio de Janeiro: ANPEd/FCPGERS, 2004.

AYRES, Ana Cléa Moreira. Tensão entre Matrizes: um estudo a partir da Faculdade de Formação de Professores/UERJ. Orientadora: Sandra Lúcia Escovedo Selles. 2006. 183 f. Tese (Doutorado em Educação) - Faculdade de Educação, Universidade Federal Fluminense, Niterói-RJ, 2006.

AYRES, Ana Cléa Moreira. et. al. Disciplina escolar Ciências e Formação de professores: aproximações sócio-históricas nas licenciaturas de curta duração. ENCONTRO NACIONAL DE DIDÁTICA E PRÁTICA DE ENSINO, 14., 2008, Porto Alegre. Anais... Porto Alegre: PUCRS, 2008, p.1-20,

BARRA, Vilma Marcassa; LORENZ, Karl Michael. Produção de materiais didáticos de ciências no Brasil, período: 1950 a 1980. Ciência \& Cultura, São Paulo, v. 38, n. 12, p. 1970-1983, jul. 1983.

BONARDI, M. C. S. Faculdade Nacional de Filosofia: um estudo da formação do professor secundário. 1990. Dissertação (Mestrado em Educação). Faculdade de Educação, Universidade Federal do Rio de Janeiro, Rio de Janeiro, 1990.

CAMPAGNOLI, Rafaela Campos; SELLES, Sandra Escovedo. Produção Curricular nos anos 1950/70: Tradução e adaptação da Versão Verde dos BSCS. CONGRESSO LUSOBRASILEIRO DE HISTÓRIA DA EDUCAÇÃO, 7., 2008. Porto. Anais... Porto: Universidade do Minho, 2008, p.1-12. 
CASSAB, Mariana. A emergência da disciplina biologia escolar (1961-1981): renovação e tradição. Orientadora: Sandra Lucia Escovedo Selles. 2011. 240f. Tese (Doutorado em Educação). Faculdade de Educação, Universidade Federal Fluminense, Niterói-RJ, 2011.

CASSAB, Mariana; SELLES, Sandra Escovedo. Investigando os rumos curriculares da disciplina História Natural no Colégio Pedro II: as atas de concursos para professores como fonte histórica. Revista Contemporânea de Educação, Rio de Janeiro, v. 3, n. 6, p. 237-258, jul/dez. 2008.

CUNHA, Luís Antônio. Polivalentes ou Polichinelos?. Ciência e Cultura, São Paulo, v. 29, n. 4, p. 420-428, abr. 1977. DÁVILA, Jerry. Diploma de Brancura: política social e racial no Brasil - 1917-1945. São Paulo: Editora UNESP, 2006. 400 p.

DEBOER, George E. A history of ideas in science education: implications for practice. New York: Teachers College, 1991. 269 p.

FÁVERO, Maria de Lourdes (org.). Universidade do Brasil: guia dos dispositivos legais. Rio de Janeiro: Editora UFRJ/ Inep, 2000. Vol. 2.

FERREIRA, Marcia Serra. A bistória da disciplina escolar Ciências no Colégio Pedro II (1960-1980). Orientador: Antonio Flávio Barbosa Moreira. 2005. Tese (Doutorado em Educação). Universidade Federal do Rio de Janeiro, Rio de Janeiro, 2005.

HAMBURGER, Amélia Império. Alguns dilemas da Licenciatura. Ciência e Cultura, São Paulo, v. 35, n. 3, p. 307-313, mar. 1983.

KRASILCHIK, Myriam. O Professor e o Currículo das Cièncias. São Paulo: Editora da Universidade de São Paulo, 1987. LIMA-TAVARES, Daniele; SELLES, Sandra Escovedo. Trajetórias da formação docente: o caso da Licenciatura Curta em Ciências nas décadas de 1960 e 1970. ENCONTRO DE HISTÓRIA DA EDUCAÇÃO DO ESTADO DO RIO DE JANEIRO, 1, 2007, Niterói. Anais... Niterói-RJ: FEUFF, 2007, p. 1-12.

LIMA-TAVARES, Daniele. A. Trajetórias da formação docente: o caso da Licenciatura Curta em Ciências das décadas de 1960 e 1970. 2006. 203 f. Dissertação (Mestrado em Educação) - Faculdade de Educação, Universidade Federal Fluminense. Niterói-RJ, 2006.

LINHARES, Célia; SILVA, Waldeck Carneiro. Formação de professores: travessia crítica de um labirinto legal. Brasília: Plano Editora, 2003.

MACEDO, Elizabeth \& LOPES, Alice Casimiro. A estabilidade do currículo disciplinar: o caso das ciências. In: LOPES, A. C. \& MACEDO, E. (orgs.) Disciplinas e integração curricular: história e políticas. Rio de Janeiro: DP\&A, 2002.

NUNES, Clarice. O "velho" e "bom" ensino secundário: momentos decisivos. Revista Brasileira de Educaşão, Rio de Janeiro, n. 14, p. 35-60, mai./ago. 2000.

PEPE, Alda Muniz. A formação do professor de Ciências - Mudanças em discussão. Revista Brasileira de Física, São Paulo, volume especial, n. 1, jul. 1976.

ROMANELLI, Otaíza. História da Educação do Brasil. Petrópolis: Vozes, 1984.

SÁ, Dominichi Miranda. A Ciência como profissão - Médicos, bacharéis e cientistas no Brasil (18951935). Rio de Janeiro: Ed. Fiocruz, 2006.

SELLES, Sandra Escovedo; FERREIRA, Marcia Serra. O professor de Ciências e o movimento renovador dos anos 1950/70. CONGRESSO LUSO-BRASILEIRO DE HISTÓRIA DA EDUCAÇÃO. 7., Porto. Anais... Porto: Universidade do Minho, 2008. p.1-12.

SELLES, Sandra Escovedo. A produção dos BSCS: livros didáticos e história da disciplina escolar Biologia. Simpósio INTERNACIONAL: LIVRO DIDÁTICO - EDUCAÇÃO E HISTÓRIA, 1., São Paulo. Anais... São Paulo: FEUSP, 2007. p. 1-17.

VICENZI, Lectícia Josephina Braga de. A fundação da Universidade do Distrito Federal e seu significado para a educação no Brasil. Forum Educacional. Rio de Janeiro, v.10, n.3, jul./set. 1986. Disponível em: <http://www.bvanisioteixeira.ufba.br/artigos/federal.html>. Acesso em 7 jul. 2010. 